\title{
MicroRNA-374a, -4680 , and $-133 b$ suppress cell proliferation through the regulation of genes associated with human cleft palate in cultured human palate cells
}

Akiko Suzuki ${ }^{1,2+}$, Aimin Li ${ }^{3,4+}$, Mona Gajera ${ }^{1 \dagger}$, Nada Abdallah ${ }^{1}$, Musi Zhang ${ }^{1,2}$, Zhongming Zhao ${ }^{3,5}$ and Junichi Iwata ${ }^{1,2,5^{*}}$ (D)

\begin{abstract}
Background: Cleft palate (CP) is the second most common congenital birth defect; however, the relationship between CP-associated genes and epigenetic regulation remains largely unknown. In this study, we investigated the contribution of microRNAs (miRNAs) to cell proliferation and regulation of genes involved in CP development.

Methods: In order to identify all genes for which mutations or association/linkage have been found in individuals with $\mathrm{CP}$, we conducted a systematic literature search, followed by bioinformatics analyses for these genes. We validated the bioinformatics results experimentally by conducting cell proliferation assays and miRNA-gene regulatory analyses in cultured human palatal mesenchymal cells treated with each miRNA mimic.

Results: We identified $131 \mathrm{CP}$-associated genes in the systematic review. The bioinformatics analysis indicated that the CP genes were associated with signaling pathways, microRNAs (miRNAs), metabolic pathways, and cell proliferation. A total 17 miRNAs were recognized as potential modifiers of human CP genes. To validate miRNA function in cell proliferation, a main cause of CP, we conducted cell proliferation/viability assays for the top 11 candidate miRNAs from our bioinformatics analysis. Overexpression of miR-133b, miR-374a-5p, and miR-4680-3p resulted in a more than 30\% reduction in cell proliferation activity in human palatal mesenchymal cell cultures. We found that several downstream target $C P$ genes predicted by the bioinformatics analyses were significantly downregulated through induction of these miRNAs (FGFR1, GCH1, PAX7, SMC2, and SUMO1 by miR-133b; ARNT, BMP2, CRISPLD1, FGFR2, JARID2, MSX1, NOG, RHPN2, RUNX2, WNT5A and ZNF236 by miR-374a-5p; and ERBB2, JADE1, MTHFD1 and WNT5A by miR-4680-3p) in cultured cells.

Conclusions: Our results indicate that miR-374a-5p, miR-4680-3p, and miR-133b regulate expression of genes that are involved in the etiology of human CP, providing insight into the association between CP-associated genes and potential targets of miRNAs in palate development.
\end{abstract}

Keywords: Cleft palate, Bioinformatics, Gene mutation, microRNA, KEGG pathway, Gene ontology

\footnotetext{
* Correspondence: Junichi.lwata@uth.tmc.edu

${ }^{\dagger}$ Akiko Suzuki, Aimin Li and Mona Gajera contributed equally to this work.

'Department of Diagnostic \& Biomedical Sciences, School of Dentistry, The

University of Texas Health Science Center at Houston, Houston, TX, USA

${ }^{2}$ Center for Craniofacial Research, The University of Texas Health Science

Center at Houston, Houston, TX, USA

Full list of author information is available at the end of the article
}

(c) The Author(s). 2019 Open Access This article is distributed under the terms of the Creative Commons Attribution 4.0 International License (http://creativecommons.org/licenses/by/4.0/), which permits unrestricted use, distribution, and reproduction in any medium, provided you give appropriate credit to the original author(s) and the source, provide a link to the Creative Commons license, and indicate if changes were made. The Creative Commons Public Domain Dedication waiver (http://creativecommons.org/publicdomain/zero/1.0/) applies to the data made available in this article, unless otherwise stated. 


\section{Background}

Cleft lip with/without cleft palate (CL/CP) is the second most common birth defect in humans worldwide [1]. CP includes both cleft lip with cleft palate (CLP) and isolated cleft palate ( $a k a$ cleft palate only, CPO). Prevalence of CP is estimated to be approximately $1 / 500$ to $1 / 2500$ live births, with ethnic and geographic variations (the highest prevalence is seen in Asian and Native American populations, and the lowest in African-derived populations) [1-3]. Approximately 70\% of CLP and 50\% of $\mathrm{CPO}$ cases are non-syndromic (i.e. there is no deformity in other parts of the body), and the remainder are syndromic (CP is part of the clinical features of the condition) [4-7]. Previous studies have identified a large number of gene mutations, chromosomal abnormalities, and teratogens in CP $[1,2]$. In addition to genetic mutations, genetic background (e.g. ethnicity, population of origin, and gender), substantially influences CP prevalence. Maternal age, smoking, alcohol consumption, obesity, and micronutrient deficiencies are known, or strongly suspected, experimental risk factors for CP. Therefore, the etiology of $\mathrm{CP}$ is complex, and its risk factors are still being elucidated [8-10]. Recent studies suggest that environmental factors control gene expression at the post-transcriptional level through epigenetic factors [11], including microRNAs (miRNAs), which are short noncoding RNAs [12].

In this study, we identified the networks and pathways of CP-associated genes and miRNAs potentially involved in the pathology of human $\mathrm{CP}$, through bioinformatics analyses of CP-associated genes and subsequent experimental validation of miRNAs that regulate cell proliferation and expression of CP-associated genes in cultured human palatal mesenchymal cells.

\section{Methods}

\section{Eligibility criteria for the systematic review}

This systematic review followed the PRISMA (Preferred Reporting Items for Systematic reviews and MetaAnalyses) guideline and corresponding checklist. The criteria for including publications were the following: 1) articles described genes associated with human CP; 2) were published as original articles; and 3) were published in English. The exclusion criteria were the following: 1) gene mutations were not described; 2) CP was not involved; 3) CP was caused by environmental factors.

\section{Information sources and search}

The Medline (Ovid), PubMed (National Library of Medicine), and EMBASE (Ovid) databases were used for the online searches. Any exceptional studies missed by the database searches were retrieved by a Scopus (Elsevier) search. The bibliographies of highly pertinent articles were examined to avoid any errors in the systematic review. RefWorks (Proquest) and Primary Excel Workbook were used to track all the search strategies and results for the screening of the titles and abstracts of papers found in the database search, as previously described [13]. All data and codebooks related to the systematic review were documented in the Primary Excel Workbook.

\section{Category enrichment analysis}

Category enrichment analysis was performed using the Kyoto Encyclopedia of Genes and Genomes (KEGG) database and the WebGestalt tool, as previously described [14]. Gene sets with a false discovery rateadjusted $p$-value $<0.05$ and at least four human $\mathrm{CP}$ genes were considered as significantly enriched categories. The Gene Ontology (GO) database [15] was used to identify categories enriched with a significant number of human CP genes, as previously described [14].

\section{miRNA-target gene analysis}

The miRTarbase, a database for experimentally validated miRNA-gene interactions, and three databases (miRanda, PITA, and TargetScan) for predicted miRNAgene interactions were used to verify the miRNA-gene relationships, as previously described [14].

\section{Cell culture}

Human palatal mesenchymal cells (HEPM cells, American Type Culture Collection) were cultured in Minimum Essential Medium Eagle-alpha modification ( $\alpha M E M)$ supplemented with $10 \%$ fetal bovine serum (FBS), penicillin/ streptomycin, and L-glutamine. The cells were plated onto 96-well cell culture plates at a density of 10,000/well and treated with a mimic for negative control, miR-27a-3p, miR-27b-3p, miR-133b, miR-203a-3p, miR-300-3p, miR374a-5p, miR-374b-5p, miR-381-3p, miR-495-3p, miR4680-3p, and miR-7854-3p (mirVana miRNA mimic, ThermoFisher Scientific) using the TransIT-X2 system (Mirus Bio LLC, Madison, WI), according to the manufacturer's protocol. Cell proliferation assays were conducted using the cell counting kit 8 (Dojindo Molecular Technologies, Gaithersburg, MD) ( $n=6$ per group).

\section{Quantitative RT-PCR}

Total RNA was extracted from HEPM cells ( $n=6$ per group) with the QIAshredder and RNeasy mini extraction kit (QIAGEN) or the miRNeasy mini extraction kit (QIAGEN), as previously described [16]. The sequences of the PCR primers are shown in Additional file 1: Table S1.

\section{Statistical analysis}

A $p$ value $<0.05$ in two-tailed student's $t$ tests was considered to be statistically significant. All the data were parametric and were represented as mean \pm standard deviation, as previously described [16]. 


\section{Results}

Literature search

A total of 5201 articles were identified in the systematic review, and 1594 duplicates were removed. The remaining 3607 articles were screened, using the titles and abstracts, independently by two screeners; 2722 papers were excluded based on the exclusion criteria. A total of 885 papers were further assessed through full-text review: 364 studies met all inclusion criteria, and 521 articles were excluded. As a result, we identified 364 studies eligible to identify genetic mutations associated with CP (Fig. 1). After collecting data from the search engines, we performed a one-by-one literature review to obtain an accurate list of human genes involved in CLP and CPO. From these 364 studies, we identified 131 genes as human CPassociated genes (Additional file 2: Table S2, additional file 3: Table S3 and Additional file 4; Table S4).

\section{KEGG pathway analysis}

Our central hypothesis is that genes associated with CP share common features among wide arrays of functions and pathways. To define functions, pathways, and networks crucial for palatal formation, we performed bioinformatics analyses of the genes from our gene list. The regulator pathway annotation was performed based on scoring and visualization of the pathways collected in the KEGG database. To summarize the cellular functions of genes from our list, we performed category enrichment analysis for a variety of functional relations. Among KEGG pathways, 28 pathways were significantly enriched with genes from the curated gene list (Table 1 and Additional file 5: Table S5). Eight of these pathways were related to cellular signaling: mitogen-activated protein kinase (MAPK) signaling pathway (16 genes), phosphatidylinositol 3'-kinase (PI3K)-Akt signaling pathway (16 genes), Rap1 signaling pathway (15 genes), Ras signaling pathway (15 genes), Hippo signaling pathway (15 genes), signaling pathways regulating pluripotency of stem cells (14 genes), WNT (Wingless-type MMTV integration site family) signaling pathway (7 genes), and transforming growth factor beta (TGF $\beta$ ) signaling pathway (7 genes). The other two pathways were related to the structural aspects of cells and tissues: regulation of actin cytoskeleton (15 genes) and adherens junction (6 genes). In addition, the enrichment of two pathways suggested metabolic involvement: metabolic pathways (7

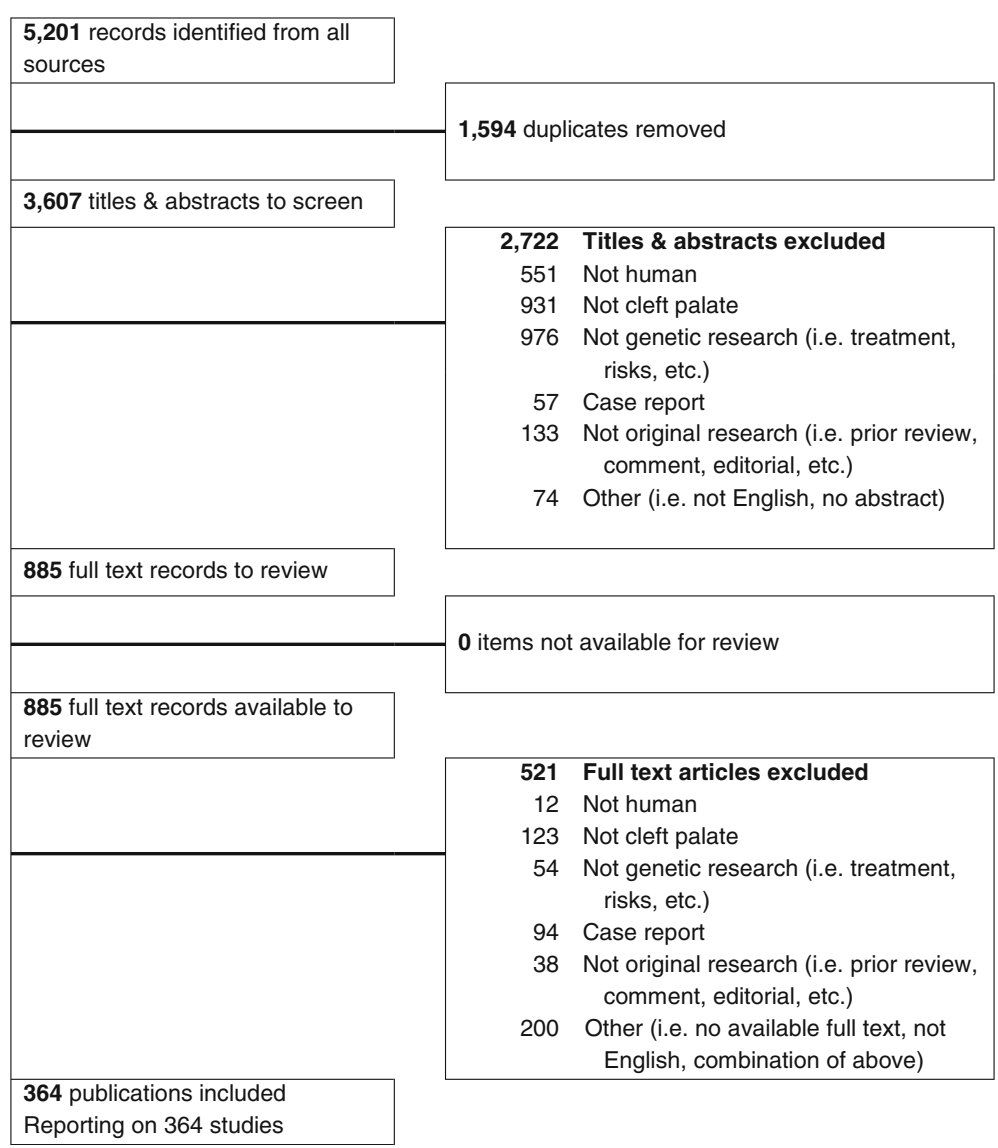

Fig. 1 PRISMA flowchart for study selection. A graphical representation of the flow of citations reviewed in the course of the systematic review was generated using a PRISMA flow diagram 
Table 1 KEGG pathways enriched with a significant number of genes involved in CP

\begin{tabular}{|c|c|}
\hline KEGG pathway & CP genes in pathway \\
\hline Pathways in cancer & $\begin{array}{l}\text { DVL3;ERBB2;FGF1;FGF2;FGF3;FGF4;FGF7;FGF8;FGF9;FGF10;FGFR1;FGFR3; } \\
\text { FGFR2;GSTP1;ARNT;LEF1;PDGFRA;PTCH1;RARA;BMP2;BMP4;TGFA; } \\
\text { TGFB1;TGFB3;WNT5A;WNT11;WNT10A;AXIN2;FGF18;WNT3A;FGF19;CDH1 }\end{array}$ \\
\hline Breast cancer & $\begin{array}{l}\text { DVL3;ERBB2;FGF1;FGF2;FGF3;FGF4;FGF7;FGF8;FGF9;FGF10;FGFR1; } \\
\text { JAG2;LEF1;WNT5A;WNT11;WNT10A;AXIN2;FGF18;WNT3A;FGF19 }\end{array}$ \\
\hline Melanoma & $\begin{array}{l}\text { FGF1;FGF2;FGF3;FGF4;FGF7;FGF8;FGF9;FGF10;FGFR1;PDGFRA;FGF18; } \\
\text { FGF19;CDH1 }\end{array}$ \\
\hline Hippo signaling pathway & $\begin{array}{l}\text { DVL3;FGF1;GDF6;LEF1;BMP2;BMP4;BMP7;TGFB1;TGFB3;WNT5A;WNT11; } \\
\text { WNT1OA;AXIN2;WNT3A;CDH1 }\end{array}$ \\
\hline Basal cell carcinoma & DVL3;LEF1;PTCH1;BMP2;BMP4;WNT5A;WNT11;WNT10A;AXIN2;WNT3A \\
\hline Signaling pathways regulating pluripotency of stem cells & $\begin{array}{l}\text { DVL3;FGF2;FGFR1;FGFR3;FGFR2;JARID2;PAX6;BMP2;BMP4;WNT5A;WNT11; } \\
\text { WNT10A;AXIN2;WNT3A }\end{array}$ \\
\hline Rap1 signaling pathway & $\begin{array}{l}\text { FGF1;FGF2;FGF3;FGF4;FGF7;FGF8;FGF9;FGF10;FGFR1;FGFR3;FGFR2;PDGFRA, } \\
\text { FGF18;FGF19;CDH1 }\end{array}$ \\
\hline Regulation of actin cytoskeleton & $\begin{array}{l}\text { FGF1;FGF2;FGF3;FGF4;FGF7;FGF8;FGF9;FGF10;FGFR1;FGFR3;FGFR2;MYH9; } \\
\text { PDGFRA;FGF18;FGF19 }\end{array}$ \\
\hline MAPK signaling pathway & $\begin{array}{l}\text { FGF1;FGF2;FGF3;FGF4;FGF7; FGF8;FGF9;FGF10;FGFR1;FGFR3;FGFR2; } \\
\text { PDGFRA;TGFB1;TGFB3;FGF18;FGF19 }\end{array}$ \\
\hline Ras signaling pathway & $\begin{array}{l}\text { FGF1;FGF2;FGF3;FGF4;FGF7;FGF8;FGF9;FGF10;FGFR1;FGFR3;FGFR2; } \\
\text { TBK1;PDGFRA;FGF18;FGF19 }\end{array}$ \\
\hline Chemical carcinogenesis & NAT2;ADH1C;CYP1A1;CYP1B1;GSTP1;GSTT1;ARNT;UGT1A7;NAT1 \\
\hline One carbon pool by folate & ALDH1L1;DHFR;MTHFD1;MTHFR;MTR \\
\hline PI3K-Akt signaling pathway & $\begin{array}{l}\text { COL2A1;FGF1;FGF2;FGF3;FGF4;FGF7;FGF8;FGF9;FGF10;FGFR1;FGFR3; } \\
\text { FGFR2;NOS3;PDGFRA;FGF18;FGF19 }\end{array}$ \\
\hline TGF-beta signaling pathway & GDF6;BMP2;BMP4;BMP7;TGFB1;TGFB3;NOG \\
\hline Prostate cancer & ERBB2;FGFR1;FGFR2;GSTP1;LEF1;PDGFRA;TGFA \\
\hline Cysteine and methionine metabolism & AHCYL2;BHMT2;MTR;BHMT;CBS \\
\hline Proteoglycans in cancer & ERBB2;FGF2;FGFR1;PTCH1;SDC2;TGFB1;WNT5A;WNT11;WNT10A;WNT3A \\
\hline Metabolism of xenobiotics by cytochrome P450 & ADH1C;CYP1A1;CYP1B1;GSTP1;GSTT1;UGT1A7 \\
\hline Adherens junction & ERBB2;FGFR1;LEF1;NECTIN1;NECTIN2;CDH1 \\
\hline EGFR tyrosine kinase inhibitor resistance & ERBB2;FGF2;FGFR3;FGFR2;PDGFRA;TGFA \\
\hline MicroRNAs in cancer & CYP1B1;ERBB2;FGFR3;PDGFRA;ABCB1;TPM1;TP63;WNT3A \\
\hline Caffeine metabolism & NAT2;NAT1 \\
\hline Tryptophan metabolism & TPH2;CYP1A1;CYP1B1;DDC \\
\hline Central carbon metabolism in cancer & ERBB2;FGFR1;FGFR3;FGFR2;PDGFRA \\
\hline Melanogenesis & DVL3;LEF1;WNT5A;WNT11;WNT10A;WNT3A \\
\hline Arginine biosynthesis & ASL;ASS1;NOS3 \\
\hline Wnt signaling pathway & DVL3;LEF1;WNT5A;WNT11;WNT10A;AXIN2;WNT3A \\
\hline Biosynthesis of amino acids & ASL;ASS1;MTR;PAH;CBS \\
\hline
\end{tabular}

genes) and endocytosis (4 genes). While no specific metabolic pathways were indicated by the KEGG analysis, the KEGG metabolic pathway network showed that these seven genes play roles in cholesterol and steroid metabolic processes: $D H O D H$ in pyrimidine metabolism; $C Y P 1 A 1$ in retinol metabolism and steroid hormone biosynthesis; DHCR7 in cholesterol synthesis; DHCR24 in steroid biosynthesis; MTHFR in folate metabolism; PAFAH1B1 in ether lipid metabolism; and NAT2 in caffeine metabolism. The remaining nine pathways included various aspects of cancer pathogenesis: pathways in cancer (32 genes), breast cancer (20 genes), melanoma (13 genes), basal cell carcinoma (10 genes), proteoglycans in cancer (10 genes), chemical carcinogenesis (9 genes), miRNAs in cancer (8 genes), prostate cancer (7 genes), and central carbon metabolism in cancer (4 genes). Interestingly, melanogenesis (6 genes) was also indicated as an enriched pathway, suggesting that the fate of cranial neural crest (CNC) cells, the majority of craniofacial mesenchymal cells and a source of melanocytes, was altered in CP. 


\section{GO functional enrichment analysis}

We analyzed the CP genes from our curated list using the GO database resource to identify the enriched functional categories. The GO biological processes showed a strong association with morphogenesis: inner ear morphogenesis (10 genes), face morphogenesis (9 genes), embryonic limb morphogenesis (8 genes), branching involved in ureteric bud morphogenesis (6 genes), embryonic cranial skeleton morphogenesis (6 genes), and branching involved in salivary gland morphogenesis (5 genes). Further enriched terms emphasized development: palate development (13 genes), skeletal system development (10 genes), and pituitary gland development (6 genes) (Table 2 and Additional file 6: Table S6). We also identified regionalization (30 genes) as an enriched term, suggesting that the arrangement and patterning of cells play important roles in palate development. All genes identified in our literature search were involved in development and morphogenesis.

Among the GO molecular functions terms, there was an enrichment of molecular binding: heparin binding (12 genes), fibroblast growth factor receptor binding (9 genes), and frizzled binding (7 genes) (Table 3 and Additional file 6: Table S6). A total of 24 out of 104 genes (23\%) were in the category of growth factor binding, growth factor receptor binding, SMAD binding, Frizzled binding, and beta-catenin binding, indicating that these molecules were directly involved in growth signaling pathway as ligands, receptors, and mediators. The remaining enriched terms in the molecular function included: chondrocyte differentiation (9 genes), osteoblast differentiation (8 genes), odontogenesis (7 genes), neural tube closure ( 7 genes), positive regulation of neuron differentiation (7 genes), and positive regulation of bone mineralization (6 genes). These enriched categories include downstream targets and modifiers of signaling pathways initiated by growth factors and morphogens.

Among the GO cellular components terms, several terms were enriched in the lipid bilayer components of cellular membranes and correlated with the enrichment of cholesterol and sterol metabolism as shown in the KEGG pathway analysis: extracellular region (36 genes), extracellular space (27 genes), cell surface (16 genes), and proteinaceous extracellular matrix (12 genes) (Table 4 and Additional file 6: Table S6). Owing to the large number of transcription factors in our list of $\mathrm{CP}$ genes, transcription factor complex (10 genes) was also an enriched term. Interestingly, additional enriched terms were specific to the neuron: synapse ( 9 genes) and axon (6 genes). This suggests that the fate of $\mathrm{CNC}$ cells, a source of the central and peripheral nervous system, might be altered and that defects in nerve formation and function may cause $\mathrm{CP}$ in humans.

\section{Environmental and epigenetic factors}

In addition to gene mutations, both genetic background and environmental factors influence $\mathrm{CP}$ prevalence. Recent studies suggest that environmental factors can regulate miRNAs that control gene expression at posttranscriptional levels [17]. To investigate how miRNAs regulate $\mathrm{CP}$ genes, we conducted an enrichment analysis of known miRNAs and their targets (Table 5 and Additional file 7: Table S7). With $p$-value $<0.005$, our list of $\mathrm{CP}$ genes was significantly enriched with the targets of 18 miRNAs: hsa-miR-27a (mir-27 family; $11 \mathrm{CP}$ genes), hsa-miR-27b (mir-27 family; 11 CP genes), hsa-miR-103 (mir-103 family; 8 CP genes), hsa-miR-133a (mir-133 family; 6 CP genes), hsa-miR-133b (mir-133 family; 11 CP genes), hsa-miR-148a-5p (mir-148 family; 4 CP genes), hsa-miR-203a-3p (mir-203 family; 9 CP genes), hsa-miR-300 (mir-154 family; $15 \mathrm{CP}$ genes), hsa-miR324-5p (mir-324 family; 9 CP genes), hsa-miR-374a (mir-374 family; $15 \mathrm{CP}$ genes), hsa-miR-374b (mir-374 family; $15 \mathrm{CP}$ genes), hsa-miR-381 (mir-154 family; 13 CP genes), hsa-miR-495 (mir-329 family; $15 \mathrm{CP}$ genes), hsa-miR-3976 (unknown family; 4 CP genes), hsa-miR4453 (unknown family; 4 CP genes), hsa-miR-4538 (unknown family; 4 CP genes), hsa-miR-4680-3p (mir-4680 family; $5 \mathrm{CP}$ genes), and hsa-miR-7854-3p (unknown family; $6 \mathrm{CP}$ genes). Thus, miRNAs may regulate the expression of multiple $\mathrm{CP}$-associated genes and play an important role in the pathology of $\mathrm{CP}$.

\section{Experimental validation}

The expression of target mRNAs is anti-correlated with miRNA expression [18]. To test whether the induction of these miRNAs caused proliferation defects through the inhibition of target genes, human palatal mesenchymal cells were treated with each miRNA mimic. The mimics for either miR-133b, miR-374a-5p or miR-4680-3p significantly inhibited (reduction of more than $30 \%$ of cell number) cell proliferation in human palatal mesenchymal cells; by contrast, treatment with mimics for miR-27a-3p, miR-27b-3p, miR-203a-3p, miR-300-3p, miR-374b-5p, and miR-495-3p resulted in no proliferation defects (Fig. 2 and Additional file 8: Table S8). The mimics for either miR-381-3p or miR-7854-3p slightly inhibited (an approximate reduction of $10 \%$ ) cell proliferation.

To identify target genes regulated by miR-133b, miR374a-5p, and miR-4680-3p, we conducted quantitative RT-PCR analyses for the predicted target genes (FGF1, FGFR1, GCH1, GSTP1, MLLT3, MYH9, PAX7, SMC2, STOM, SUMO1, and ZNF236 for hsa-miR-133b; ARNT, BMP2, CRISPLD1, FGFR1, JARID2, MSX1, NOG, NTN1, RHPN2, RUNX2, TNS1, WNT5A, and ZNF236 for hsamiR-374a-5p; and ERBB2, JADE1, MTHFD1, and WNT5A for hsa-miR-4680-3p) in human palatal mesenchymal cells treated with either miR-133b, miR-374a-5p, or miR-4680- 
Table 2 GO biological process terms enriched with a significant number of genes involved in CP

\begin{tabular}{|c|c|}
\hline GO biological process & $\mathrm{CP}$ genes in biological process category \\
\hline $\begin{array}{l}\text { GO:0045893 } \\
\text { positive regulation of transcription, DNA-templated }\end{array}$ & $\begin{array}{l}\text { WNT5A, FGF7, WNT3A, GDF6, TGFB3, PAX6, FGF10, TP63, CDH1, PAX3, TGFB1, } \\
\text { ARNT, FOXF2, BCL3, RARA, RUNX2, FGF2, BMP4, DVL3, BMP2, LEF1, TBX1, IRF6, } \\
\text { IRF7, FOXE1, TFAP2A, ROR2, PTCH1, WNT11, BMP7 }\end{array}$ \\
\hline $\begin{array}{l}\text { GO:0014066 } \\
\text { regulation of phosphatidylinositol 3-kinase signaling }\end{array}$ & $\begin{array}{l}\text { FGF19, FGFR2, FGF18, FGFR1, FGF8, FGF7, FGFR3, FGF9, ERBB2, PDGFRA, FGF10, } \\
\text { FGF1, FGF2, FGF3, FGF4 }\end{array}$ \\
\hline $\begin{array}{l}\text { GO:0036092 } \\
\text { phosphatidylinositol-3-phosphate biosynthetic process }\end{array}$ & $\begin{array}{l}\text { FGF19, FGFR2, FGF18, FGFR1, FGF8, FGF7, FGFR3, FGF9, FGF10, FGF1, FGF2, } \\
\text { FGF3, FGF4 }\end{array}$ \\
\hline $\begin{array}{l}\text { GO:0046854 } \\
\text { phosphatidylinositol phosphorylation }\end{array}$ & $\begin{array}{l}\text { FGF19, FGFR2, FGF18, FGFR1, FGF8, FGF7, FGFR3, FGF9, ERBB2, PDGFRA, FGF10, } \\
\text { FGF1, FGF2, FGF3, FGF4 }\end{array}$ \\
\hline $\begin{array}{l}\text { GO:0008543 } \\
\text { fibroblast growth factor receptor signaling pathway }\end{array}$ & $\begin{array}{l}\text { FGF19, FGFR2, FGF18, FGFR1, FGF8, FGF7, FGFR3, FGF9, FGF10, UBB, FGF1, } \\
\text { FGF2, FGF3, FGF4 }\end{array}$ \\
\hline $\begin{array}{l}\text { GO:0048015 } \\
\text { phosphatidylinositol-mediated signaling }\end{array}$ & $\begin{array}{l}\text { FGF19, FGFR2, FGF18, FGFR1, FGF8, FGF7, FGFR3, FGF9, ERBB2, PDGFRA, FGF10, } \\
\text { FGF1, FGF2, FGF3, FGF4 }\end{array}$ \\
\hline $\begin{array}{l}\text { GO:0060021 } \\
\text { palate development }\end{array}$ & $\begin{array}{l}\text { WNT5A, SUMO1, MSX1, GABRB3, WNT3A, FOXF2, TGFB3, LEF1, TFAP2A, COL2A1, } \\
\text { WNT11, VAX1, COL11A2 }\end{array}$ \\
\hline $\begin{array}{l}\text { GO:0018108 } \\
\text { peptidyl-tyrosine phosphorylation }\end{array}$ & $\begin{array}{l}\text { FGFR2, FGF18, FGFR1, FGF8, FGF7, FGFR3, FGF9, RYK, ERBB2, PDGFRA, FGF10, } \\
\text { ROR2, FGF1, FGF2, FGF3, FGF4 }\end{array}$ \\
\hline $\begin{array}{l}\text { GO:0045944 } \\
\text { positive regulation of transcription from RNA polymerase II promoter }\end{array}$ & $\begin{array}{l}\text { FGFR2, WNT5A, NOG, TBK1, WNT3A, TGFB3, PAX6, FGF10, TP63, PAX3, GREM1, } \\
\text { TGFB1, ARNT, JADE1, PAX9, PAX7, FOXF2, BCL3, RARA, FGF1, FGF2, FGF4, BMP4, } \\
\text { BMP2, MAFB, LEF1, GRHL3, TBX1, MSX1, IRF7, TFAP2A, UBB, BMP7 }\end{array}$ \\
\hline $\begin{array}{l}\text { GO:0051781 } \\
\text { positive regulation of cell division }\end{array}$ & FGFR2, FGF8, FGF7, FGF9, TGFB3, TGFA, FGF1, FGF2, TGFB1, FGF3, FGF4 \\
\hline GO:0042475 & BMP4, BMP2, MSX1, JAG2, TP63, LEF1, FGF10, TBX1, BMP7, RUNX2, FGF4 \\
\hline
\end{tabular}

odontogenesis of dentin-containing tooth

GO:0050679

positive regulation of epithelial cell proliferation

GO:0008284

positive regulation of cell proliferation

GO:0060325

face morphogenesis

GO:0000165

MAPK cascade

GO:0001837

epithelial to mesenchymal transition

GO:0042472

inner ear morphogenesis

GO:0002062

chondrocyte differentiation

GO:0008285

negative regulation of cell proliferation

GO:0070374

positive regulation of ERK1 and ERK2 cascade

GO:0042060

wound healing

GO:0001759

organ induction

GO:0030326

embryonic limb morphogenesis

GO:0045892

negative regulation of transcription, DNA-templated

\section{GO:0090090}

negative regulation of canonical Wnt signaling pathway

GO:0042476

odontogenesis

FGFR2, BMP4, NOG, FGF7, FGF9, ERBB2, TGFA, FGF10, TBX1, FGF1, TGFB1

FGFR2, FGF19, FGFR1, FGF18, FGF8, FGF7, FGFR3, FGF9, WNT3A, LEF1, TBX1, GREM1, NTN1, TGFB1, PDGFRA, TGFA, RARA, FGF1, FGF2, RUNX2, FGF3, FGF4

NOG, MSX1, CRISPLD1, PAX9, CRISPLD2, TGFB3, LEF1, TBX1, TGFB1

FGFR2, FGF19, FGFR1, FGF18, FGF8, FGFR3, FGF7, FGF9, ERBB2, FGF10, TGFB1, PDGFRA, UBB, FGF1, FGF2, FGF3, FGF4

FGFR2, WNT5A, BMP2, NOG, FOXF2, LEF1, WNT11, BMP7, TGFB1

FGFR2, FGFR1, MAFB, FGF9, WNT3A, TFAP2A, ROR2, COL2A1, TBX1, NTN1

BMP4, FGFR1, BMP2, FGFR3, FGF9, COL2A1, COL11A2, RUNX2, TGFB1

BMP4, BMP2, CYP1B1, JARID2, TGFB3, FGF10, BRIP1, TIMP2, TGFB1, MSX1, IRF6, ROR2, TFAP2A, NOS3, RARA, AXIN2, BMP7, FGF2

FGF19, FGFR2, BMP4, FGF18, BMP2, FGF8, FGFR3, PDGFRA, FGF10, FGF1, FGF2, TGFBI, FGF4

WNT5A, NOG, ERBB2, PDGFRA, TGFB3, TGFA, FGF10, GRHL3, FGF2, TPM1

BMP4, FGFR1, FGF8, FGF10, FGF1, FGF2

FGFR1, FGF9, TP63, LEF1, PTCH1, SP8, GREM1, BMP7

WNT5A, BMP4, BMP2, JARID2, TBX22, LEF1, TP63, GREM1, TGFB1, SUMO1, PAX9, FOXF2, FOXE1, BCL3, TFAP2A, WNT11, RARA, BMP7, RUNX2

WNT5A, JADE1, DVL3, BMP2, NOG, ROR2, LEF1, WNT11, UBB, GREM1, AXIN2, MLLT3

FGFR2, BMP4, WNT1OA, FGF8, PAX9, TGFB3, AXIN2 
Table 2 GO biological process terms enriched with a significant number of genes involved in CP (Continued)

\begin{tabular}{ll}
\hline GO biological process & CP genes in biological process category \\
\hline $\begin{array}{l}\text { GO:0043547 } \\
\text { positive regulation of GTPase activity }\end{array}$ & FGFR2, FGF19, DVL3, FGFR1, FGF18, FGF8, FGFR3, FGF7, FGF9, ERBB2, FGF10, \\
$\begin{array}{l}\text { GO:0009086 } \\
\text { methionine biosynthetic process }\end{array}$ & GRHL3, ARHGAP29, PDGFRA, WNT11, AXIN2, FGF1, FGF2, FGF3, FGF4 \\
$\begin{array}{l}\text { GO:0042487 } \\
\text { regulation of odontogenesis of dentin-containing tooth } \\
\text { GO:0030509 }\end{array}$ & $B M P 4$, WNT10A, BMP2, FGF8, RUNX2 \\
BWP BHT, MTRR \\
BMP4, BMP2, NOG, FGF8, GDF6, ROR2, LEF1, BMP7, RUNX2
\end{tabular}

BMP signaling pathway

GO:0001701

in utero embryonic development

GO:0043410

positive regulation of MAPK cascade

GO:0046655

folic acid metabolic process

GO:0042493

response to drug

GO:0010628

positive regulation of gene expression

GO:0003148

outflow tract septum morphogenesis

GO:0001501

skeletal system development

GO:0001525

angiogenesis

GO:0060445

branching involved in salivary gland morphogenesis

GO:0045165

cell fate commitment

GO:0002053

positive regulation of mesenchymal cell proliferation

GO:0031069

hair follicle morphogenesis

GO:0000122

negative regulation of transcription from RNA polymerase ॥ promoter

GO:0021983

pituitary gland development

GO:0048701

embryonic cranial skeleton morphogenesis

GO:0001934

positive regulation of protein phosphorylation

GO:0032355

response to estradiol

GO:0030501

positive regulation of bone mineralization

GO:0060395

SMAD protein signal transduction

GO:0043066

negative regulation of apoptotic process

GO:0001657

ureteric bud development

GO:0001649

osteoblast differentiation
FGFR2, FGFR1, BMP2, NOG, MSX1, WNT3A, TGFB3, JAG2, PTCH1, NOS3,

MYH9, TPM1

FGFR2, FGFR1, BMP2, FGFR3, RYK, FGF9, FGF10, TBX1, TIMP2

MTHFD1, MTHFR, ALDH1L1, DHFR, SLC19A1, MTRR

DVL3, MTHFR, FGF8, CYP1A1, ASS1, SLC6A4, TGFA, CDH1, PTCH1, ABCB1, ABCA1, TIMP2, GAD1, TGFB1

WNT10A, BMP2, NOG, FGF8, FGF9, WNT3A, ERBB2, SLC6A4, PAX6, TFAP2A, LEF1, WNT11, TGFB1

FGFR2, BMP4, DVL3, FGF8, TBX1, RARA

FGFR1, BMP2, NOG, FGFR3, TCOF1, JAG2, TP63, COL2A1, COL11A2, BMP7

FGFR2, FGFR1, FGF18, CYP1B1, FGF9, TGFA, FGF10, TBX1, NOS3, STAB2, FGFI, MYH9

FGFR2, FGFR1, FGF8, FGF7, BMP7

FGFR2, WNT5A, WNT1OA, BMP2, FGF8, ROR2, WNT11

FGFR2, WNT5A, FGFR1, FGF9, TP63, TBX1

FGFR2, WNT10A, FGF7, FOXE1, TP63, FGF10

BMP4, FGFR2, FGFR1, NOG, BMP2, JARID2, FGF9, TBX22, PAX6, LEF1, TP63, VAX1, TGFB1, MSX1, IRF7, FOXE1, TFAP2A, PTCH1, RARA, UBB

BMP4, NOG, MSX1, PAX6, FGF10, CDH1

FGFR2, BMP4, PDGFRA, TFAP2A, TBX1, RUNX2

FGF19, BMP4, DVL3, BMP2, WNT3A, ERBB2, TBX1, AXIN2, TGFB1

ASS1, SLC6A4, FGF10, PTCH1, RARA, BMP7, TGFB1, GSTP1

BMP4, BMP2, TGFB3, TFAP2A, BMP7, TGFB1

BMP4, BMP2, GDF6, TGFB3, ROR2, BMP7, TGFB1

BMP4, WNT5A, TP63, LEF1, GREM1, MSX1, PAX7, TGFA, BCL3, TFAP2A, RARA, WNT11, UBB, GSTP1, FGF4

FGFR2, BMP4, FGFR1, RARA, BMP7, TGFB1

BMP4, BMP2, NOG, FGF9, WNT3A, LEF1, WNT11, RUNX2 
Table 2 GO biological process terms enriched with a significant number of genes involved in CP (Continued)

\begin{tabular}{|c|c|}
\hline GO biological process & $\mathrm{CP}$ genes in biological process category \\
\hline $\begin{array}{l}\text { GO:0071300 } \\
\text { cellular response to retinoic acid }\end{array}$ & WNT5A, WNT3A, SLC6A4, TBX1, RARA, WNT11, ABCA1 \\
\hline $\begin{array}{l}\text { GO:0001658 } \\
\text { branching involved in ureteric bud morphogenesis }\end{array}$ & BMP4, BMP2, FGF8, PTCH1, GREM1, FGF2 \\
\hline $\begin{array}{l}\text { GO:0000187 } \\
\text { activation of MAPK activity }\end{array}$ & WNT5A, BMP2, TGFB3, TGFA, FGF10, UBB, FGF1, FGF2 \\
\hline $\begin{array}{l}\text { GO:0048762 } \\
\text { mesenchymal cell differentiation }\end{array}$ & FGFR2, FGFR1, BMP2, BMP7 \\
\hline $\begin{array}{l}\text { GO:0030324 } \\
\text { lung development }\end{array}$ & FGFR2, WNT5A, FGF18, CRISPLD2, NOS3, FGF1, FGF2 \\
\hline $\begin{array}{l}\text { GO:0001843 } \\
\text { neural tube closure }\end{array}$ & MTHFD1, BMP4, NOG, GRHL3, PTCH1, RARA, TGFB1 \\
\hline $\begin{array}{l}\text { GO:0045666 } \\
\text { positive regulation of neuron differentiation }\end{array}$ & BMP4, FGFR1, BMP2, GDF6, RARA, TIMP2, BMP7 \\
\hline $\begin{array}{l}\text { GO:0010862 } \\
\text { positive regulation of pathway-restricted SMAD protein } \\
\text { phosphorylation }\end{array}$ & BMP4, BMP2, GDF6, TGFB3, BMP7, TGFB1 \\
\hline
\end{tabular}

3p. PAX6 and TGFA were excluded from the gene expression experiments because Pax6 is expressed only in the cephalic ectoderm [19] and TGFA is expressed at the medial edge epithelium of the fusing palatal shelves [20, 21]. The expression of ERBB2, JADE1, MTHFD1 and WNT5A was significantly downregulated in cultured

Table $3 \mathrm{GO}$ molecular function terms enriched with a significant number of genes involved in CP

\begin{tabular}{ll}
\hline GO molecular function & CP genes in molecular function category \\
\hline GO:0046934 & FGF19, FGFR2, FGF18, FGFR1, FGF8, FGF7, \\
phosphatidylinositol-4,5- & FGFR3, FGF9, ERBB2, PDGFRA, FGF10, FGF1, \\
bisphosphate 3-kinase & FGF2, FGF3, FGF4 \\
activity & \\
G0:0016303 & FGF19, FGFR2, FGF18, FGFR1, FGF8, FGF7, \\
1-phosphatidylinositol-3- & FGFR3, FGF9, FGF10, FGF1, FGF2, FGF3, \\
kinase activity & FGF4 \\
G0:0008083 & BMP4, FGF19, FGF18, BMP2, FGF8, FGF7, \\
growth factor activity & FGF9, GDF6, JAG2, TGFB3, FGF10, TGFB1, \\
& TGFA, FGF1, BMP7, FGF2, FGF3, FGF4 \\
G0:0005088 & FGF19, FGFR2, FGF18, FGFR1, FGF8, FGF7, \\
Ras guanyl-nucleotide & FGFR3, FGF9, ERBB2, PDGFRA, FGF10, FGF1, \\
exchange factor activity & FGF2, FGF3, FGF4 \\
GO:0005104 & FGF19, FGF8, FGF7, FGF9, FGF10, FGF1, FGF2, \\
fibroblast growth factor & FGF3, FGF4 \\
receptor binding & \\
GO:0004713 & FGFR2, FGF18, FGFR1, FGF8, FGF7, FGFR3, \\
protein tyrosine kinase & FGF9, RYK, ERBB2, FGF10, FGF1, FGF2, FGF3, \\
activity & FGF4 \\
GO:0008201 & FGFR2, BMP4, FGFR1, FGF7, CRISPLD2, FGF9, \\
heparin binding & FGF10, PTCH1, FGF1, BMP7, FGF2, FGF4 \\
GO:0005109 & WNT5A, DVL3, WNT10A, RYK, WNT3A, ROR2, \\
frizzled binding & WNT11 \\
GO:0042803 & FGFR2, FGFR1, NOG, GDF6, SLC6A4, NECTIN1, \\
protein homodimerization & NECTIN2, TBX1, MYH9, MID1, TGFB1, GCH1, \\
activity & UGT1A7, STOM, PDGFRA, TFAP2A, PCYT1A, CBS \\
\hline &
\end{tabular}

human palatal mesenchymal cells treated with miR-46803p mimic (Fig. 3a). To further evaluate the anticorrelation of miRNAs and target genes, we treated cells with a miR-4680-3p inhibitor and found that expression of ERBB2 and MTHFD1 was significantly upregulated (Fig. 3b). Therefore, these results indicate that $E R B B 2$ and MTHFD1 are downstream target genes of miR-4680-3p in cultured human palate cells.

Next, we investigated the downstream target genes of miR-374a-5p. We found that expression of ARNT, BMP2, CRISPLD1, FGFR2, JARID2, MSX1, NOG, RUNX2, WNT5A, and ZNF236 was significantly downregulated in cultured cells treated with miR-374a-5p mimic (Fig. 4a). By contrast, a miR-374a-5p inhibitor induced the expression of CRISPLD1, FGFR2, JARID2, MSX1, TNS1, and ZNF236 (Fig. 4b). Therefore, these results indicate that miR-374a-5p can regulate the expression of CRISPLD1, FGFR2, JARID2, MSX1, and ZNF236 in a dose-dependent manner in cultured human palate cells.

Lastly, we assessed the predicted miR-133b downstream target genes. We found that expression of FGFR1, GCH1, PAX7, SMC2, and SUMO1 was significantly downregulated in cultured cells treated with miR133b mimic (Fig. 5a), but expression of GCH1, MLLT3, PAX7, STOM2 and ZNF236 was significantly increased with a miR-133b inhibitor (Fig. 5b). These results indicate that miR-133b can regulate the expression of $G C H 1$ and $P A X 7$ in a dose-dependent manner in cultured human palate cells. Taken together, our experimental results provide proof of function for some of the predicted target genes (ERBB2 and MTHFD1 for miR-4680-3p; CRISPLD1, FGFR2, JARID2, MSX1, and ZNF236 for miR-374a-5p; and GCH1 and PAX7 for miR-133b) in cultured human palate cells. 
Table $4 \mathrm{GO}$ cellular component terms enriched with a significant number of genes involved in CP

\begin{tabular}{ll}
\hline GO cellular component & CP genes in cellular component category \\
\hline GO:0005576 & FGF19, FGFR2, WNT5A, FGF18, FGFR1, FGF8, \\
extracellular region & NOG, FGFR3, FGF7, FGF9, WNT3A, GDF6, \\
& TGFB3, FGF10, COL2A1, CDH1, MMP3, TIMP2, \\
& TGFB1, CRISPLD1, CRISPLD2, COL11A2, FGF1, \\
& PRSS35, FGF2, FGF3, FGF4, BMP4, WNT10A, \\
& BMP2, NECTIN1, TCN2, NTN1, WNT11, WDR1, \\
& BMP7 \\
G0:0005615 & WNT5A, FGF18, FGF8, NOG, FGF9, GDF6, \\
extracellular space & WNT3A, TGFB3, FGF10, COL2A1, GREM1, \\
& TIMP2, MMP3, TGFB1, SERPINA6, TGFA, FGF1, \\
& FGF2, BMP4, WNT10A, BMP2, TCN2, STOM, \\
& WNT11, UBB, BMP7, GSTP1 \\
GO:0005578 & WNT5A, BMP4, WNT10A, CRISPLD2, WNT3A, \\
proteinaceous extracellular & WNT11, COL11A2, FGF1, TIMP2, MMP3, \\
matrix & TGFB1, MMP25 \\
GO:0009986 & WNT5A, FGFR2, BMP2, FGFR3, WNT3A, TGFB3, \\
cell surface & FGF10, NECTIN2, ABCB1, GREM1, TIMP2, \\
& TGFB1, SDC2, TNS1, TGFA, RARA \\
\hline &
\end{tabular}

Table 5 miRNA families that target a motif in a significant number of genes involved in $C P$

\begin{tabular}{|c|c|}
\hline miRNA & $\mathrm{CP}$ genes with target MOTIF \\
\hline hsa-miR-300 & $\begin{array}{l}\text { ABCA1;CRISPLD1;FGF7;FGFR2;FOXF2;GABRB3;GAD1; } \\
\text { JAG2;LEF1;MID1;MLLT3;PTCH1;WNT5A;CRISPLD2; } \\
\text { GREM1 }\end{array}$ \\
\hline hsa-miR-381 & $\begin{array}{l}\text { ABCA1;CRISPLD 1;FGF7;FGFR2;FOXF2;GABRB3;GAD1; } \\
\text { JAG2;LEF1;MID1;MLLT3;PTCH1;WNT5A }\end{array}$ \\
\hline hsa-miR-495 & $\begin{array}{l}\text { ARNT;BMP2;CYP1B1;FGF1;FGF19;FGF7;GAD1;JAG2; } \\
\text { MLLT3;NTN1;PRSS35;PTCH1;RUNX2;SUMO1;VAX1 }\end{array}$ \\
\hline hsa-miR-374a & $\begin{array}{l}\text { ARNT;BMP2;CRISPLD1;FGFR2;JARID2;MSX1;NOG; } \\
\text { NTN1;PAX6;RHPN2;RUNX2;TGFA;TNS1;WNT5A; } \\
\text { ZNF236 }\end{array}$ \\
\hline hsa-miR-374b & $\begin{array}{l}\text { ARNT;BMP2;CRISPLD1;FGFR2;JARID2;MSX1;NOG; } \\
\text { NTN1;PAX6;RHPN2;RUNX2;TGFA;TNS1;WNT5A; } \\
\text { ZNF236 }\end{array}$ \\
\hline hsa-miR-4680-3p & ERBB2;JADE1;MTHFD1;TBK1;WNT5A \\
\hline hsa-miR-203a-3p & $\begin{array}{l}\text { CDH1;FGF2;GREM1;PAX6;RUNX2;STOM;SUMO1; } \\
\text { TBK1;TP63 }\end{array}$ \\
\hline hsa-miR-7854-3p & BRIP1;CBS;CRISPLD2;FGF19;FGFR1;MSX1 \\
\hline hsa-miR-133b & $\begin{array}{l}\text { FGF1;FGFR1;GCH1;MLLT3;MYH9;PAX7;SMC2;STOM; } \\
\text { SUMO1;ZNF236;GSTP1 }\end{array}$ \\
\hline hsa-miR-27a & $\begin{array}{l}\text { ABCA1;BCL3;GABRB3;GCH1;GDF6;GREM1;MN1;PAX9; } \\
\text { PDGFRA;RARA;SUMO1 }\end{array}$ \\
\hline hsa-miR-27b & $\begin{array}{l}\text { ABCA1;BCL3;GABRB3;GCH1;GDF6;GREM1;MN1;PAX9; } \\
\text { PDGFRA;RARA;SUMO1 }\end{array}$ \\
\hline hsa-miR-4453 & CBS;MYHA;RYK;SP8 \\
\hline hsa-miR-4538 & CBS;MYHA;RYK;SP8 \\
\hline hsa-miR-103 & AXIN2;FGF2;FGF7;FGFR2;GAD1;MYH9;TPM1;WNT3A \\
\hline hsa-miR-133a & FGF1;GCH1;MLLT3;MYH9;SUMO1;ZNF236 \\
\hline hsa-miR-148a-5p & ABCA1;CRISPLD2;CYP1B1;TNS1 \\
\hline hsa-miR-324-5p & $\begin{array}{l}\text { GDF6;RUNX2;SLC6A4;ARNT;ASS1;CBS;MTHFD1;PAX3; } \\
\text { TCOF1 }\end{array}$ \\
\hline hsa-miR-3976 & AHCYL2;CYP1B1;GDF6;WDR1 \\
\hline
\end{tabular}

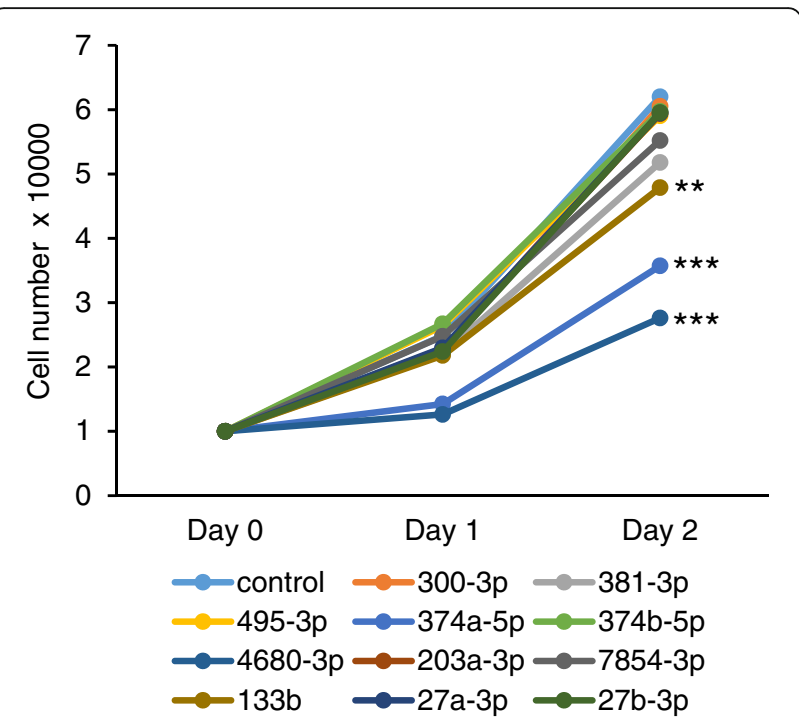

Fig. 2 Effect of predicted miRNAs on cell proliferation. Cell proliferation assays in human palatal fibroblasts treated with the indicated miRNA mimics. Negative control (control, light blue), miR300-3p (orange), miR-381-3p (light gray), miR-495-3p (yellow), miR374a-5p (blue), miR-374b-5p (light green), miR-4680-3p (dark blue), miR-203a-3p (brown), miR-7854-3p (gray), miR-133b (light brown), miR-27a-3p (navy), and miR27b-3p (green). ${ }^{* *} p<0.01$, ${ }^{* *} p<0.001$. Each treatment group was compared with the control. $n=6$ per group

\section{Discussion}

$\mathrm{CP}$-associated genes were grouped based on their common features through GO and KEGG analyses. As expected, most of the pathways highlighted have been shown to be involved in the growth and development process. For example, in the top enriched pathways, the MAPK pathway regulated by growth factors (e.g. hedgehog, TGF $\beta$, and WNT) can regulate a wide variety of cellular functions crucial for palatogenesis, including cell proliferation and differentiation [22]. The GO term annotation showed that the transcription process is the most significantly enriched (67\%). This suggests that transcription factors regulated by cellular pathways that control the growth and fusion of the palatal shelves are crucial for palate development. For example, loss of TGF $\beta$ receptor type II (Tgfbr2) results in ectopic p38 MAPK activation and altered gene expression of $A d c y 2$ and $P d e 4 b$, which regulate lipid metabolism and cause $C P$ in mice [23]. In the enriched cellular component terms, we identified a focus on membranes and other structures dependent on lipids and lipid bilayers for their structure and function. Six genes in the CP gene list were involved in the cilium: GLI2, GLI3, KIF7, OFD1, PAFAH1B1, and WDR19. GLI2 and GLI3 locate in the primary cilium and translocate into the nuclei upon binding of hedgehog ligands to activate and/or inactivate hedgehog signaling [24, 25]. KIF7 is a motor protein in all cilia that regulates hedgehog signaling 


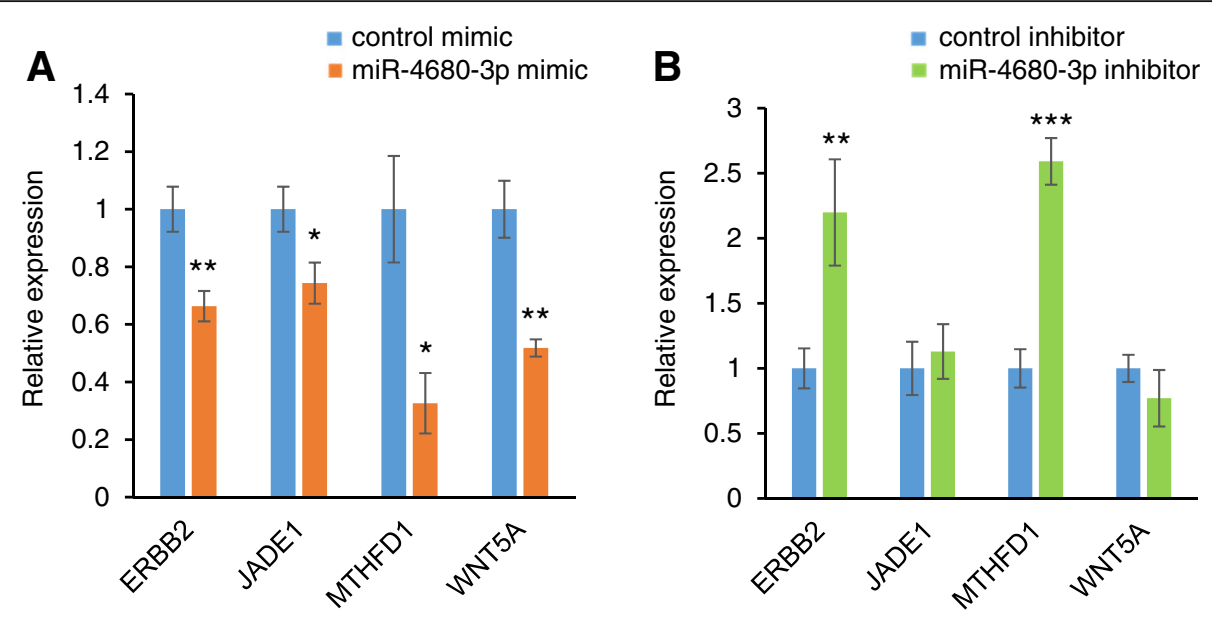

Fig. 3 Effect of miR-4680-3p on predicted target genes. a Quantitative RT-PCR for the indicated genes after treatment with negative control (light blue) or miR-4680-3p mimic (orange). ${ }^{*} p<0.05,{ }^{* *} p<0.01$. Each treatment group was compared with the control. $\mathrm{n}=6$ per group. $\mathbf{b}$ Quantitative RT-PCR for the indicated genes after treatment with negative control (light blue) or miR-4680-3p inhibitor (light green). ${ }^{* *} p<0.01$, *** $p<0.001$. Each treatment group was compared with the control. $\mathrm{n}=6$ per group

[26-28], and OFD1 and WDR19 localize around the basal body at the base of cilia [29-31]. PAFAH1B1 is a regulator of the dynein motor proteins that traffic molecules back down the cilium [32-34]. Thus, the accumulating evidences indicate that primary cilia contain abundant hedgehog receptors and mediators, and that they regulate hedgehog signaling activity.

In non-syndromic $\mathrm{CP}$, maternal environmental factors most likely increase the risk of $\mathrm{CP}$ with a link to some single-nucleotide polymorphisms (SNPs), while these

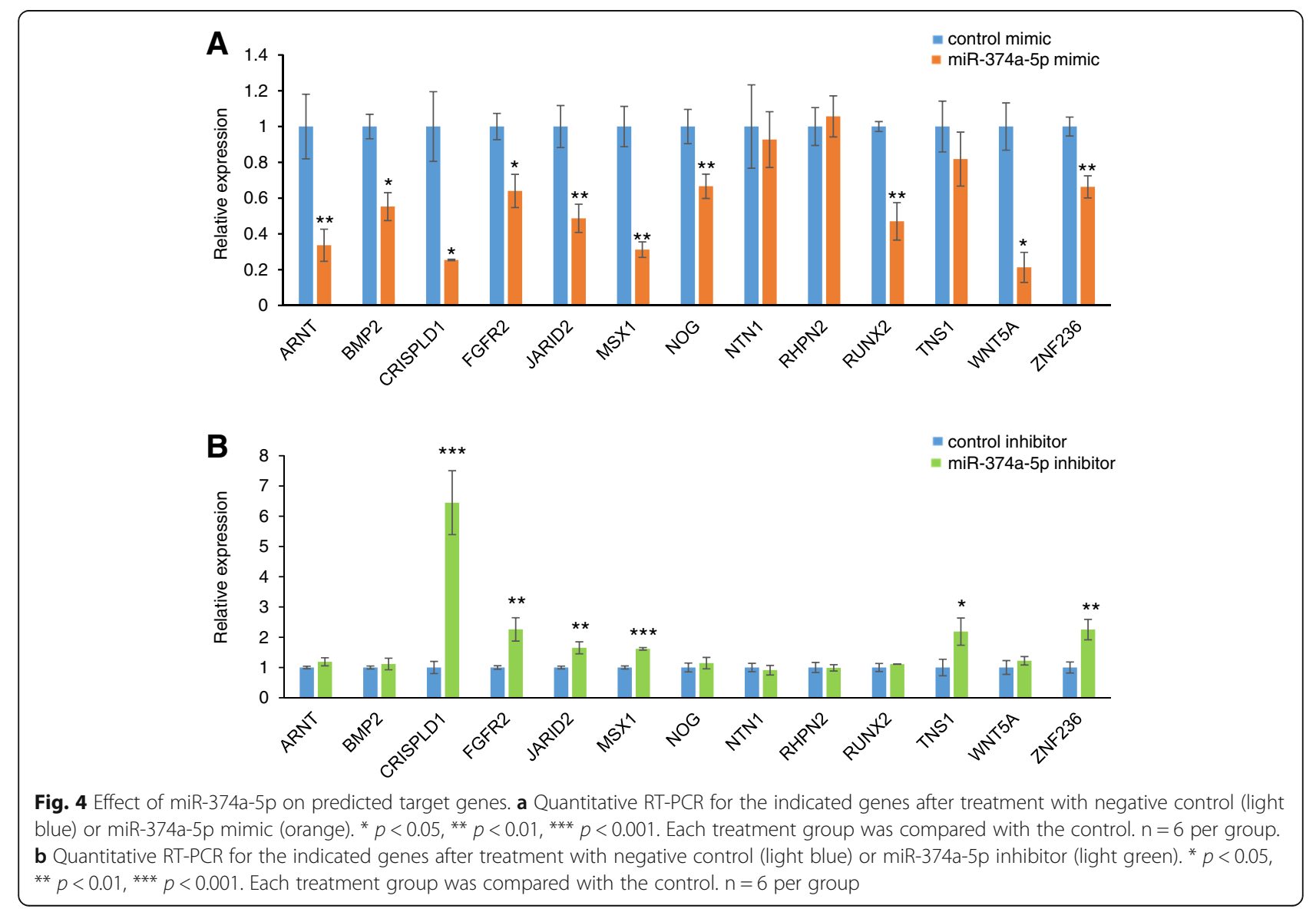



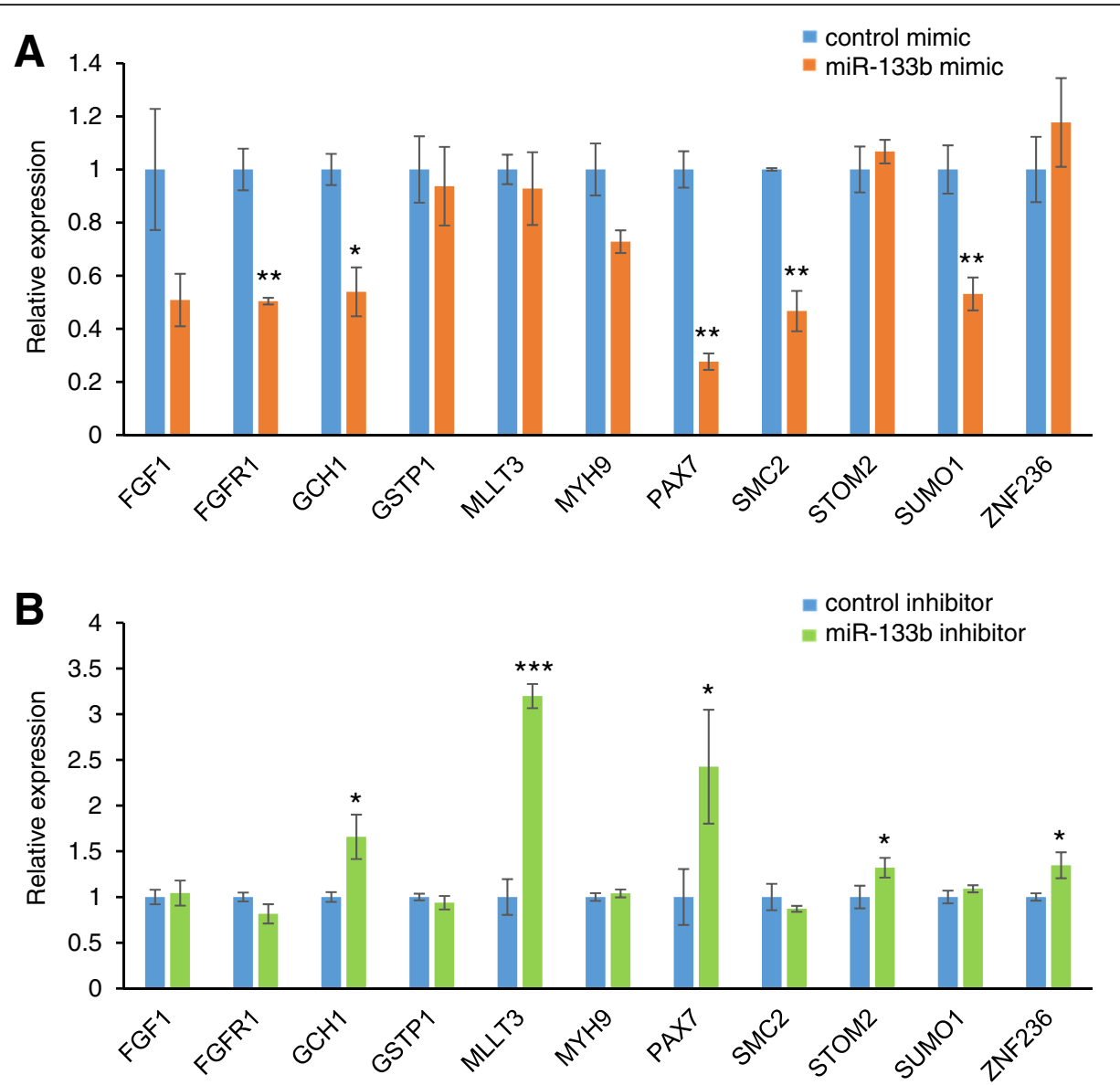

Fig. 5 Effect of miR-133b on predicted target genes. a Quantitative RT-PCR for the indicated genes after treatment with negative control (light blue) or miR-133b mimic (orange). ${ }^{*} p<0.05$, ${ }^{*} p<0.01$. Each treatment group was compared with the control. $\mathrm{n}=6$ per group. $\mathbf{b}$ Quantitative RT-PCR for the indicated genes after treatment with negative control (light blue) or miR-133b inhibitor (light green). ${ }^{*} p<0.05,{ }^{* * *} p<0.001$. Each treatment group was compared with the control. $n=6$ per group

SNPs alone do not achieve genome-wide significance. For example, SNPs in GSTP1, TBK1 and ZNF236 seem to be associated with a higher risk of $\mathrm{CP}$ with maternal smoking [35, 36]. Similarly, SNPs in MLLT3 and SMC2 seem to increase CP risk with alcohol consumption during the peri-conceptual period [35]. Importantly, smoking and alcohol consumption, which are associated not only with cancer but also with other diseases, alter miRNA expression in the serum and cells [37-41]. During development, maternal alcohol consumption directly influences miRNA expression in mice and zebrafish [42-44]. Recent studies suggest that miRNAs may pass through the placenta from mothers to embryos to directly regulate embryogenesis $[45,46]$. In this study, we found that some CP genes are regulated by multiple miRNAs, two miRNAs for GSTP1, 26 miRNAs for MLLT3, 29 miRNAs for $S M C 2$, 22 miRNAs for TBK1, and 56 miRNAs for ZNF236. These CP genes may have a higher chance of being altered by environmental factors.

\section{Conclusions}

Our computational analyses have predicted the possible roles and mechanisms of miRNAs altered by environmental factors in CP. Overexpression of miR-374a, miR-4680, and miR-133b suppresses cell proliferation through the regulation of their target genes in cultured HEPM cells. While this systematic review shows much strength in the collection of CP-associated genes, it presents some limitations in the identification of causative genes due to the complex etiology of CP (e.g. genes not specific to CP, CP that is a part of syndromic features, no complete penetrance, secondary $\mathrm{CP}$ affected by other craniofacial anomalies).

\section{Additional files}

Additional file 1: Table S1. PCR primer sets used in this study. (XLSX 12 kb)

Additional file 2: Table S2. Gene mutations found in cases of human CP. (PDF $704 \mathrm{~kb}$ ) 
Additional file 3: Table S3. Genes with significant contribution to human cleft palate. (XLSX $89 \mathrm{~kb})$

Additional file 4: Table S4. Genes without significant contribution to human cleft palate. (XLSX $38 \mathrm{~kb}$ )

Additional file 5: Table S5. KEGG pathways enriched with human cleft palate genes. (XLSX $14 \mathrm{~kb}$ )

Additional file 6: Table S6. GO terms enriched with human cleft palate genes. (XLSX $19 \mathrm{~kb}$ )

Additional file 7: Table S7. MicroRNA enrichment analysis of human cleft palate genes. (XLSX 9 kb)

Additional file 8: Table S8. Transfection efficiency of miRNA mimic and inhibitor. (PDF $51 \mathrm{~kb}$ )

\section{Abbreviations}

CL/CP: Cleft lip with/without cleft palate; CLO: Cleft lip only; CLP: Cleft lip with cleft palate; CNC: Cranial neural crest; CPO: Cleft palate only; miRNA: MicroRNA

\section{Acknowledgments}

We thank Dr. Hiroki Yoshioka for assistance with the experiments, and Mrs. Helena VonVille, Ms. Pegah Ebadat, and Ms. Afreen Ansari for helping with the literature search.

\section{Authors' contributions}

Conceived and designed the study: AS and JI. Performed the systematic literature search and review: MG and NA. Performed bioinformatics analyses: $A L$ and ZZ. Conducted experiments: AS, MZ, and Jl. Analyzed the data: AL, $A S, Z Z$, and JI. Wrote the paper: AS, ZZ, and JI. All authors have read and approved the final manuscript.

\section{Funding}

This study was supported by grants from the National Institute of Dental and Craniofacial Research, NIH (DE024759, DE026208, DE026767, and DE026509 to JI), and a faculty start-up fund from the UTHealth School of Dentistry to J. ZZ is supported by NIH grants R01LM012806 and R21CA196508. The funders had no role in study design, data collection and analysis, decision to publish, or preparation of the manuscript.

\section{Availability of data and materials}

All the data from this study are available as supplemental information.

\section{Ethics approval and consent to participate}

Not applicable.

\section{Consent for publication}

Not applicable.

\section{Competing interests}

The authors declare that they have no competing interests.

\section{Author details}

${ }^{1}$ Department of Diagnostic \& Biomedical Sciences, School of Dentistry, The University of Texas Health Science Center at Houston, Houston, TX, USA ${ }^{2}$ Center for Craniofacial Research, The University of Texas Health Science Center at Houston, Houston, TX, USA. ${ }^{3}$ Center for Precision Health, School of Biomedical Informatics, The University of Texas Health Science Center at Houston, Houston, TX, USA. ${ }^{4}$ School of Computer Science and Engineering, Xi'an University of Technology, Xi'an 710048, Shaanxi, China. ${ }^{5}$ MD Anderson Cancer Center UTHealth Graduate School of Biomedical Sciences, 1941 East Road, BBS 4208, Houston, TX 77054, USA

\section{Received: 29 October 2018 Accepted: 31 May 2019}

Published online: 01 July 2019

\section{References}

1. Leslie EJ, Marazita ML. Genetics of cleft palate. Am J Med Genet C Semin Med Genet. 2013:163C(4):246-58.

2. Ferguson MW. Palate development. Development. 1988;103(Suppl):41-60.
3. Iwata J, Parada C, Chai Y. The mechanism of TGF-beta signaling during palate development. Oral Dis. 2011;17(8):733-44.

4. Stanier P, Moore GE. Genetics of cleft lip and palate: syndromic genes contribute to the incidence of non-syndromic clefts. Hum Mol Genet. 2004: 13(Spec 1):R73-81.

5. Marazita ML, Field LL, Cooper ME, Tobias R, Maher BS, Peanchitlertkajorn S, Liu YE. Genome scan for loci involved in cleft lip with or without cleft palate, in Chinese multiplex families. Am J Hum Genet. 2002;71(2):349-64.

6. Marazita ML, Field LL, Cooper ME, Tobias R, Maher BS, Peanchitlertkajorn S, Liu YE. Nonsyndromic cleft lip with or without cleft palate in China: assessment of candidate regions. Cleft Palate Craniofac J. 2002;39(2):149-56.

7. Jones MC. Etiology of facial clefts: prospective evaluation of 428 patients. Cleft Palate J. 1988:25(1):16-20

8. Dixon MJ, Marazita ML, Beaty TH, Murray JC. Cleft lip and palate: understanding genetic and environmental influences. Nat Rev Genet. 2011;12(3):167-78.

9. Murray JC. Gene/environment causes of cleft lip and/or palate. Clin Genet. 2002;61(4):248-56

10. Jugessur A, Murray JC. Orofacial clefting: recent insights into a complex trait. Curr Opin Genet Dev. 2005;15(3):270-8.

11. Lillycrop KA, Burdge GC. Maternal diet as a modifier of offspring epigenetics. J Dev Orig Health Dis. 2015;6(2):88-95.

12. Ross JS, Carlson JA, Brock G. miRNA: the new gene silencer. Am J Clin Pathol. 2007;128(5):830-6.

13. Sangani D, Suzuki A, VonVille H, Hixson JE, Iwata J. Gene mutations associated with temporomandibular joint disorders: a systematic review. OAlib. 2015;2(6):e1583.

14. Suzuki A, Abdallah N, Gajera M, Jun G, Jia P, Zhao Z, Iwata J. Genes and microRNAs associated with mouse cleft palate: a systematic review and bioinformatics analysis. Mech Dev. 2018;150:21-7.

15. Subramanian A, Tamayo P, Mootha VK, Mukherjee S, Ebert BL, Gillette MA, Paulovich A, Pomeroy SL, Golub TR, Lander ES, et al. Gene set enrichment analysis: a knowledge-based approach for interpreting genome-wide expression profiles. Proc Natl Acad Sci U S A. 2005;102(43):15545-50.

16. Suzuki A, Pelikan RC, Iwata J. WNT/beta-catenin signaling regulates multiple steps of Myogenesis by regulating step-specific targets. Mol Cell Biol. 2015;35(10):1763-76.

17. Guo AY, Sun J, Jia P, Zhao Z. A novel microRNA and transcription factor mediated regulatory network in schizophrenia. BMC Syst Biol. 2010;4:10.

18. Ambros $V$. The functions of animal microRNAs. Nature. 2004:431(7006):350-5.

19. Elso C, Lu X, Weisner PA, Thompson HL, Skinner A, Carver E, Stubbs L. A reciprocal translocation dissects roles of Pax6 alternative promoters and upstream regulatory elements in the development of pancreas, brain, and eye. Genesis. 2013;51(9):630-46.

20. Dixon MJ, Ferguson MW. The effects of epidermal growth factor, transforming growth factors alpha and beta and platelet-derived growth factor on murine palatal shelves in organ culture. Arch Oral Biol. 1992;37(5):395-410.

21. lamaroon A, Tait B, Diewert VM. Cell proliferation and expression of EGF, TGF-alpha, and EGF receptor in the developing primary palate. J Dent Res. 1996:75(8):1534-9.

22. Seger R, Krebs EG. The MAPK signaling cascade. FASEB J. 1995;9(9):726-35.

23. Iwata J, Suzuki A, Pelikan RC, Ho TV, Sanchez-Lara PA, Chai Y. Modulation of lipid metabolic defects rescues cleft palate in Tgfbr2 mutant mice. Hum Mo Genet. 2014;23(1):182-93.

24. Briscoe J, Therond PP. The mechanisms of hedgehog signalling and its roles in development and disease. Nat Rev Mol Cell Biol. 2013;14(7):416-29.

25. Goetz SC, Anderson KV. The primary cilium: a signalling Centre during vertebrate development. Nat Rev Genet. 2010;11(5):331-44.

26. He M, Subramanian R, Bangs F, Omelchenko T, Liem KF Jr, Kapoor TM, Anderson KV. The kinesin-4 protein Kif7 regulates mammalian hedgehog signalling by organizing the cilium tip compartment. Nat Cell Biol. 2014;16(7):663-72

27. Liem KF Jr, He M, Ocbina PJ, Anderson KV. Mouse Kif7/Costal2 is a ciliaassociated protein that regulates sonic hedgehog signaling. Proc Natl Acad Sci U S A. 2009:106(32):13377-82.

28. Cheung HO, Zhang X, Ribeiro A, Mo R, Makino S, Puviindran V, Law KK, Briscoe Jui CC. The kinesin protein Kif7 is a critical regulator of Gli transcription factors in mammalian hedgehog signaling. Sci Signal. 2009;2(76):ra29.

29. Romio L, Wright V, Price K, Winyard PJ, Donnai D, Porteous ME, Franco B, Giorgio G, Malcolm S, Woolf AS, et al. OFD1, the gene mutated in 
oral-facial-digital syndrome type 1 , is expressed in the metanephros and in human embryonic renal mesenchymal cells. J Am Soc Nephrol : JASN. 2003;14(3):680-9.

30. Romio L, Fry AM, Winyard PJ, Malcolm S, Woolf AS, Feather SA. OFD1 is a centrosoma//basal body protein expressed during mesenchymal-epithelial transition in human nephrogenesis. J Am Soc Nephrol : JASN. 2004;15(10):2556-68.

31. Efimenko E, Blacque OE, Ou G, Haycraft CJ, Yoder BK, Scholey JM, Leroux MR, Swoboda P. Caenorhabditis elegans DYF-2, an orthologue of human WDR19, is a component of the intraflagellar transport machinery in sensory cilia. Mol Biol Cell. 2006;17(11):4801-11.

32. Huang J, Roberts AJ, Leschziner AE, Reck-Peterson SL. Lis1 acts as a "clutch" between the ATPase and microtubule-binding domains of the dynein motor. Cell. 2012;150(5):975-86.

33. Torisawa T, Nakayama A, Furuta K, Yamada M, Hirotsune S, Toyoshima YY. Functional dissection of LIS1 and NDEL1 towards understanding the molecular mechanisms of cytoplasmic dynein regulation. J Biol Chem. 2011;286(3):1959-65.

34. Pedersen LB, Rompolas P, Christensen ST, Rosenbaum JL, King SM. The lissencephaly protein Lis1 is present in motile mammalian cilia and requires outer arm dynein for targeting to Chlamydomonas flagella. J Cell Sci. 2007;120(Pt 5):858-67.

35. Beaty TH, Ruczinski I, Murray JC, Marazita ML, Munger RG, Hetmanski JB, Murray T, Redett RJ, Fallin MD, Liang KY, et al. Evidence for geneenvironment interaction in a genome wide study of nonsyndromic cleft palate. Genet Epidemiol. 2011;35(6):469-78.

36. Krapels IP, Raijmakers-Eichhorn J, Peters WH, Roelofs HM, Ras F, SteegersTheunissen RP, Eurocran Gene-Environment Interaction G. The I,105V polymorphism in glutathione S-transferase P1, parental smoking and the risk for nonsyndromic cleft lip with or without cleft palate. Eur J Hum Genet. 2008;16(3):358-66.

37. Ignacio C, Hicks SD, Burke P, Lewis L, Szombathyne-Meszaros Z, Middleton FA. Alterations in serum microRNA in humans with alcohol use disorders impact cell proliferation and cell death pathways and predict structural and functional changes in brain. BMC Neurosci. 2015;16:55.

38. Mullany LE, Herrick JS, Wolff RK, Stevens JR, Slattery ML. Association of cigarette smoking and microRNA expression in rectal cancer: insight into tumor phenotype. Cancer Epidemiol. 2016:45:98-107.

39. Schembri F, Sridhar S, Perdomo C, Gustafson AM, Zhang X, Ergun A, Lu J, Liu G, Zhang X, Bowers J, et al. MicroRNAs as modulators of smokinginduced gene expression changes in human airway epithelium. Proc Natl Acad Sci U S A. 2009;106(7):2319-24.

40. Shi B, Gao H, Zhang T, Cui Q. Analysis of plasma microRNA expression profiles revealed different cancer susceptibility in healthy young adult smokers and middle-aged smokers. Oncotarget. 2016;7(16):21676-85.

41. Wang G, Wang R, Strulovici-Barel Y, Salit J, Staudt MR, Ahmed J, Tilley AE, Yee-Levin J, Hollmann C, Harvey BG, et al. Persistence of smoking-induced dysregulation of miRNA expression in the small airway epithelium despite smoking cessation. PLoS One. 2015;10(4):e0120824.

42. Mandal C, Halder D, Jung KH, Chai YG. Maternal alcohol consumption and altered miRNAs in the developing fetus: context and future perspectives. J Appl Toxicol. 2018;38(1):100-7.

43. Soares AR, Pereira PM, Ferreira V, Reverendo M, Simoes J, Bezerra AR, Moura $G R$, Santos MA. Ethanol exposure induces upregulation of specific microRNAs in zebrafish embryos. Toxicol Sci. 2012;127(1):18-28.

44. Wang LL, Zhang Z, Li Q, Yang R, Pei X, Xu Y, Wang J, Zhou SF, Li Y. Ethanol exposure induces differential microRNA and target gene expression and teratogenic effects which can be suppressed by folic acid supplementation. Hum Reprod. 2009;24(3):562-79.

45. Gross N, Kropp J, Khatib H. MicroRNA signaling in embryo development. Biology (Basel). 2017;6(3):E34.

46. Li J, Zhang Y, Li D, Liu Y, Chu D, Jiang X, Hou D, Zen K, Zhang CY. Small non-coding RNAs transfer through mammalian placenta and directly regulate fetal gene expression. Protein Cell. 2015;6(6):391-6.

\section{Publisher's Note}

Springer Nature remains neutral with regard to jurisdictional claims in published maps and institutional affiliations.

\section{Ready to submit your research? Choose BMC and benefit from}

- fast, convenient online submission

- thorough peer review by experienced researchers in your field

- rapid publication on acceptance

- support for research data, including large and complex data types

- gold Open Access which fosters wider collaboration and increased citations

- maximum visibility for your research: over $100 \mathrm{M}$ website views per year

At BMC, research is always in progress.

Learn more biomedcentral.com/submissions 